CAHIER DE RECHERCHE $\# 0907 \mathrm{E}$

Département de science économique

Faculté des sciences sociales

Université d'Ottawa
WORKING PAPER \#0907E

Department of Economics

Faculty of Social Sciences

University of Ottawa

\title{
Pro-Poor Tax reforms, with an Application to Mexico*
}

\author{
Jean-Yves Duclos $^{\dagger}$, Paul Makdissi ${ }^{\ddagger}$, and Abdelkrim Araar ${ }^{\S}$
}

May 2009

\footnotetext{
${ }^{*}$ This work was carried out with support from CRSH, FQRSC and the Poverty and Economic Policy Research Network, which is financed by the Government of Canada through the International Development Research Centre and the Canadian International Development Agency, and by the Australian Agency for International Development. We are grateful to Sami Bibi for useful comments and to Lourdes Trevio and Jorge Valero Gil for having given us access to ENIGH data and for their invitation to present the preliminary results of this paper at a 2006 Symposium that took place in Monterrey, and to the Symposium participants for valuable comments.

† Département d'économique and CIRPÉE, Université Laval, Canada, and Institut d'Analisi Economica (CSIC), Spain; email: jyves@ecn.ulaval.ca

‡ Department of Economics, University of Ottawa, P.O. Box 450, Station A Ottawa, Ontario Canada, K1N 6N5; Email: paul.makdissi@uottawa.ca

${ }^{\S}$ Département d'économique and CIRPÉE, Pavillon de Sève, Université Laval, Québec, Canada, G1K 7P4; Email: aabd@ecn.ulaval.ca
} 


\begin{abstract}
This paper proposes a new methodology to test for whether indirect tax reforms are pro-poor. The methodology extends stochastic dominance techniques and enables identifying tax reforms that will necessarily be deemed absolutely or relatively pro-poor by a wide spectrum of poverty analysts. The statistical properties of the various estimators are also derived in order to make the method implementable using survey data. The methodology is used to assess the pro-poorness of possible reforms to Mexico's indirect tax system. This leads to the identification of several possible pro-poor tax reforms in that country.
\end{abstract}

Key words: Stochastic dominance, pro-poor changes, tax reforms, indirect taxation, poverty, Mexico

JEL Classification: D12, D63, H21, I32.

\title{
Résumé
}

Cet article propose une nouvelle méthode permettant de déterminer si une réforme de la fiscalité indirecte est pro-pauvre. Cette méthode adapte des techniques de dominance stochastique permettant ainsi d'identifier les réformes fiscales qui seront considérées absolument ou relativement pro-pauvre par un large éventail d'analystes de la pauvreté. Les propriétés statistiques des différents estimateurs sont dérivées afin de rendre la méthode applicable à des données d'enquêtes. La méthode est utilisée afin d'identifier plusieurs réformes de la fiscalité indirecte mexicaine qui serait pro-pauvres.

Mots clés: Dominance stochastique, changements pro-pauvre, réformes fiscales, taxation indirecte, pauvreté, Mexique

Classification JEL: D12, D63, H21, I32. 


\section{Introduction}

The last decade has seen several contributions on whether growth is "propoor". A central issue is whether the poor's benefits from growth exceed some norm 1 . This norm may be absolute or relative to the changes in the entire distribution of income, as recently discussed for instance in Duclos (2009). A similar issue applies to the effect of public policy. We may wish for instance to assess whether a fiscal reform is "pro-poor", in the sense that the benefits that the poor derive from it exceed some norm. Unfortunately, as with many other distributive assessments, the precise definition that can be given to the pro-poorness of an indirect tax reform is essentially a matter of normative judgement and can be open to the criticism of being arbitrary to at least some extent. Elements of arbitrariness arise inter alia in the choice of a poverty line to separate the poor from the non-poor and in the choice of an aggregative procedure to summarize the reform's impact on the poor. ${ }^{2}$ To show how one can reduce these sources of arbitrariness in understanding pro-poorness is the first main objective of this paper.

The second main objective of the paper is to assess how and whether a (marginal) tax reform can be considered to be pro-poor. Santoro (2007) categorizes the economic literature on the impact of marginal tax reforms into three different approaches. The first is based on Ahmad and Stern (1984) and uses a specific social welfare function. The second identifies directions for marginal tax reforms based on classes of social welfare functions that display an aversion to inequality and that are symmetric — this was introduced by Yitzhaki and Thirsk (1990), Yitzhaki and Slemrod (1991) and Mayshar and Yitzhaki (1996). The third approach recognizes that marginal tax reforms can also be used as instruments for changing poverty and is based inter alia on Makdissi and Wodon (2002), Duclos, Makdissi, and Wodon (2008) and Liberati (2003).

This paper extends this third approach by testing for whether indirect tax reforms can be considered to be pro-poor. By this, it is meant that an indirect tax reform must be deemed to be "equitable towards the poor" or "in favor of the poor", in the sense that the benefits of the reform must accrue (in some sense to be

\footnotetext{
${ }^{1}$ See, among many recent interesting contributions to that issue, Bruno, Ravallion, and Squire (1998), United Nations (2000), Eastwood and Lipton (2001), Ravallion (2001), Dollar and Kraay (2002), World Bank (2002) and Bourguignon (2003).

${ }^{2}$ Different approaches have been proposed to separate the poor from the non-poor and to compute indices of "growth pro-poorness". See, for instance, McCulloch and Baulch (1999), Ravallion and Datt (2002), Kakwani, Khandker, and Son (2003), Ravallion and Chen (2003), Klasen (2003), Son (2004), Essama-Nssah (2005), and Araar, Duclos, Audet, and Makdissi (2007).
} 
made precise later) "more" to the poor, or that its costs must hurt "less" the poor.

The remainder of the paper is divided as follows. Section 2 introduces the notation and derives the main analytical results. Section 3 proposes estimators and derives sampling distributions for the tools needed to test for tax pro-poorness. For the important case of first-order pro-poorness, these estimators involve nonparametric regressions. Section 4 applies the methodology to Mexico's indirect tax system using the 2004 Mexican ENIGH database. Section 5 concludes. The Appendix (Section 6) contains proofs of the paper's main results.

\section{Notation and methodological framework}

\subsection{Poverty Measurement}

We first start with the presentation of rather general views of how poverty and tax pro-poorness can be assessed. For simplicity, suppose that poverty indices are additive $^{-3}$ and therefore take the form

$$
P(z)=\int_{0}^{\omega} p(y, z) d F(y),
$$

where $y$ is real income, $z$ is the poverty line (in real terms), $F(\cdot)$ is the cumulative distribution function of income with support over $[0, \omega]$, and $p(y, z)$ is a function that measures the poverty of an individual with an income $y$ and using a poverty line $z$. We suppose that $p(y, z) \geq 0$ and that $p(y, z)=0$ for all $y>z$. Duclos and Makdissi (2003) use the properties of $P(z)$ to define classes of poverty indices $\Pi^{s}(z)$ for some order $s$. These classes are defined by:

$$
\Pi^{s}(z)=\left\{\begin{array}{l|c}
p(y, z) \in \widehat{C}^{s}(z), \\
P(z) \mid \begin{array}{c}
i \\
(-1)^{(i)}(y, z) \geq 0 \text { for } i=0,1,2, \ldots, s, \\
p^{(t)}(z, z)=0 \text { for } t=0,1,2, \ldots, s,
\end{array}
\end{array}\right\}
$$

where $p^{(i)}(y, z)$ represents the $i$-th derivative of $p(y, z)$ with respect to $y$ and $\widehat{C}^{s}$ is the set of continuous functions that are $s$-times differentiable on $[0, \omega]$.

For poverty indices $P \in \Pi^{1}(z)$, an increase in the income of any one individual will weakly reduce the poverty index. This class of indices is thus Paretian.

\footnotetext{
${ }^{3}$ The Foster, Greer, and Thorbecke (1984) indices are an example of popular additive poverty measures. Other examples of additive indices can be found in Watts (1968), Clark, Hemming, and Ulph (1981) and Chakravarty (1983).
} 
The indices are also symmetrical since exchanging incomes between two individuals will not affect poverty (by the property of the distribution function in (1)). This type of indices can thus be said to satisfy Pen (1971)'s principles for comparing distributions (see Duclos, Makdissi, and Wodon (2008)).

The poverty indices included in $\Pi^{2}(z)$ are also convex. This implies that they respect the Pigou-Dalton principle of transfer, a principle that states that a transfer from any one individual to a poorer individual should weakly decrease poverty. In addition to obeying the above principles, the poverty indices that belong to $\Pi^{3}(z)$ must also obey the Kolm (1976) principle of transfers, which states that a PigouDalton transfer that takes place at the bottom of the distribution should have a greater impact on poverty than one taking place higher up in the distribution. Hence, a progressive transfer that occurs within a lower part of the distribution will reduce poverty even if it is accompanied by a symmetric regressive transfer higher up in the distribution. Indices of a class $\Pi^{s}(z)$ with $s$ greater then 3 can be interpreted by using the generalized transfer principle proposed by Fishburn and Willig (1984). This generalized principle states that the greater the order $s$, the greater is the sensibility of an index to changes occurring in a lower part of the distribution.

\subsection{Identifying pro poor reforms}

Let us now suppose that one wishes to test whether an indirect tax reform can be considered to be pro-poor. We consider three possible scenarios through which this can be done.

1. The government wishes to implement a marginal reduction in the tax (or a marginal increase in the subsidy) on good $i$, without attempting to offset the fall in total government revenue (possibly because the government is running a budget surplus).

2. The government wishes to implement a marginal increase in the tax (or a marginal decrease in the subsidy) on good $i$, without attempting to offset the increase in total government revenue (possibly because the government is running a budget deficit).

3. The government wishes to implement a revenue-neutral indirect tax reform. It must therefore finance a marginal tax reduction on good $i$ (or a marginal increase in its subsidy) with a marginal increase in the tax (or a marginal decrease in the subsidy) on good $j \neq i$. 
Now assume that producer prices are held constant and, for expositional simplicity, set them to 1 so that $q=e+t$, where $q$ is the vector of current consumption prices, $e$ is a vector of ones, and $t$ is the vector of indirect taxes. The impact of a marginal change $d t_{i}$ to the tax on a good $i$ will impact the poverty level of an individual with income $y$ by

$$
\frac{\partial p(y, z)}{\partial t_{i}}=p^{(1)}(y, z) \frac{\partial y}{\partial t_{i}}
$$

Using Roy's identity and setting the vector of reference prices to the current price vector, the change in real income produced by a marginal change in the tax on good $i$ is given by (see for instance Besley and Kanbur 1988)

$$
\frac{\partial y}{\partial t_{i}}=-x_{i}(y, q)
$$

where $x_{i}(y, q)$ is the Marshallian demand of good $i$ at the vector of current prices, $q$. Introducing (4) into (3), we have that

$$
\frac{\partial p(y, z)}{\partial t_{i}}=-p^{(1)}(y, z) x_{i}(y, q) .
$$

We do not wish, however, to determine if a tax reform reduces or increases poverty, but whether it can be considered pro-poor in the sense of Duclos (2009) and Araar, Duclos, Audet, and Makdissi (2007). This requires distinguishing between relative and absolute pro-poorness. We will say that a tax reform is $R$-propoor for relative pro-poorness and $A$-pro-poor for absolute pro-poorness. In the growth terminology of Duclos (2009) and Araar, Duclos, Audet, and Makdissi (2007), relative pro-poorness is checked by comparing $P(z)$ using $F_{1}((1+g) y)$ for a posterior distribution $F_{1}(y)$ to $P(z)$ for an initial distribution $F_{0}(y)$, using a relative "norm" $g$ (to be discussed later). Absolute pro-poorness with an absolute norm $a$ (also discussed below) is checked by comparing $P(z)$ using $F_{1}(y+a)$ for a posterior distribution $F_{1}(y)$ to $P(z)$ for an initial distribution $F_{0}(y)$. Formally:

Definition 1 A movement from an initial distribution $F_{0}$ to a posterior distribution $F_{1}$ is judged relatively pro-poor by an index $P(z)$ if

$$
\int_{0}^{\infty} p(y, z) d F_{1}((1+g) y)-\int_{0}^{\infty} p(y, z) d F_{0}(y)<0 .
$$


Definition 2 A movement from an initial distribution $F_{0}$ to a posterior distribution $F_{1}$ is judged absolutely pro-poor by an index $P(z)$ if

$$
\int_{0}^{\infty} p(y, z) d F_{1}(y+a)-\int_{0}^{\infty} p(y, z) d F_{0}(y)<0 .
$$

For the purposes of this paper, we will assume that the relative norm $g$ is set to the growth rate of average real income ${ }^{4}$ and that the absolute norm $a$ is set to the absolute value of the change in average real income. ${ }^{5}$ Let then:

$$
\begin{aligned}
y^{* R} & =\frac{y}{1+g}, \\
y^{* A} & =y-a, \\
\frac{\partial p^{* \eta}(y, z)}{\partial t_{i}} & =p^{(1)}(y, z) \frac{\partial y^{* \eta}}{\partial t_{i}}, \eta \in\{A, R\} .
\end{aligned}
$$

We now wish to determine how $y^{* R}$ and $y^{* A}$ vary with a marginal variation in $t_{i}$. As noted by Duclos, Makdissi, and Wodon (2008), the average impact of $d t_{i}$ on real income in the total population is given by $d t_{i}$ times the average consumption of good $i$, which is denoted as $X_{i}(q)$ :

$$
X_{i}(q)=\int_{0}^{\infty} x_{i}(y, q) d F(y) .
$$

Using this, the proportional change in average real income (following a change $d t_{i}$ in a tax rate $t_{i}$ ) is given by

$$
-\frac{X_{i}(q)}{\mu} d t_{i}
$$

where $\mu=\int y d F(y)$ is average income. The absolute change in average real income is given by

$$
-X_{i}(q) d t_{i} .
$$

\footnotetext{
${ }^{4}$ This is consistent with the view of Kakwani and Pernia (2000) (p.3) that "promoting pro-poor growth requires a strategy that is deliberately biased in favor of the poor so that the poor benefit proportionately more than the rich."

${ }^{5}$ Generalizations of this to other settings would not be difficult, by setting for instance $g$ to growth in some quantiles (such as the median), or by setting $a$ to 0 (which would be equivalent to arguing that a change is pro-poor if it increases the poor's absolute living standards $-e . g$., Ravallion and Chen 2003).
} 
In order to determine the impact of a marginal variation in $t_{i}$ on $y^{* R}$ and $y^{* A}$, we must subtract from the gross impact on real income given by (4) the impact on real income of the change in the pro-poor norm given by (8) and (9). This leads to

$$
\frac{\partial y^{* R}}{\partial t_{i}}=-x_{i}(y, q)+y \frac{X_{i}(q)}{\mu}
$$

and

$$
\frac{\partial y^{* A}}{\partial t_{i}}=-x_{i}(y, q)+X_{i}(q)
$$

Using (14) and (15), we obtain

$$
\frac{\partial p^{* R}(y, z)}{\partial t_{i}}=-p^{(1)}(y, z)\left[x_{i}(y, q)-y \frac{X_{i}(q)}{\mu}\right]
$$

and

$$
\frac{\partial p^{* A}(y, z)}{\partial t_{i}}=-p^{(1)}(y, z)\left[x_{i}(y, q)-X_{i}(q)\right] .
$$

To obtain the impact on total poverty, we integrate (16) and (17) over the entire income distribution. The result is

$$
\frac{\partial P^{* R}(z)}{\partial t_{i}}=-\int_{0}^{\infty} p^{(1)}(y, z)\left[x_{i}(y, q)-y \frac{X_{i}(q)}{\mu}\right] d F(y)
$$

and

$$
\frac{\partial P^{* A}(z)}{\partial t_{i}}=-\int_{0}^{\infty} p^{(1)}(y, z)\left[x_{i}(y, q)-X_{i}(q)\right] d F(y) .
$$

We can now introduce pro-poor consumption dominance curves $\left(C D^{\eta: s}\right), \eta \in$ $\{A, R\}$ and $s \in\{1,2,3 \ldots\}\}^{6}$ Those pro-poor consumption dominance curves are defined as:

$$
C D_{i}^{R: s}(z)= \begin{cases}{\left[\frac{x_{i}(z, q)}{X_{i}(q)}-\frac{z}{\mu}\right] f(y)} & \text { for } s=1 \\ \int_{0}^{z} C D_{i}^{R: s-1}(y) d y & \text { for } s \geq 2\end{cases}
$$

\footnotetext{
${ }^{6}$ See Makdissi and Wodon (2002) for an introduction to consumption dominance curves.
} 
and

$$
C D_{i}^{A: s}(z)= \begin{cases}{\left[\frac{x_{i}(z, q)}{X_{i}(q)}-1\right] f(z)} & \text { for } s=1 \\ \int_{0}^{z} C D_{i}^{A: s-1}(y) d y & \text { for } s \geq 2 .\end{cases}
$$

By integration by parts, (20) and (21) can be written for $s=2,3, \ldots$ as

$$
C D_{i}^{R: s}(z)=\frac{1}{(s-2) !} \int_{0}^{z}\left[\frac{x_{i}(y, q)}{X_{i}(q)}-\frac{y}{\mu}\right](z-y)^{s-2} d F(y)
$$

and

$$
C D_{i}^{A: s}(z)=\frac{1}{(s-2) !} \int_{0}^{z}\left[\frac{x_{i}(y, q)}{X_{i}(q)}-1\right](z-y)^{s-2} d F(y) .
$$

This leads to our first main analytical result.

Theorem 1 A marginal decrease in the tax on good $i$ is $\eta$-pro-poor $(\eta \in\{A, R\})$ for all indices $P(z) \in \Pi^{s}(z)$ and for all poverty lines $z \in\left[0, z^{+}\right]$if and only if

$$
C D_{i}^{\eta: s}(z) \geq 0, \forall z \in\left[0, z^{+}\right]
$$

It is useful to interpret Theorem 1 in the context of the first two scenarios listed at the beginning of Section 2.2 on page 4. For this, let us first classify goods according to their income elasticity, $\varepsilon_{i}^{y}$.

Definition 3 A good $i$ is said to be an inferior good if $\varepsilon_{i}^{y}<0$ and a normal good if $\varepsilon_{i}^{y}>0$, for all $y$.

Definition 4 A normal good is said to be a necessary good if $\varepsilon_{i}^{y}<1$ and a luxury $\operatorname{good}$ if $\varepsilon_{i}^{y}>1$, for all $y$.

Four simple remarks can then be made as a corollary to Theorem 1 .

Corollary 1 Regardless of the value of $s$ and $z^{+}$:

1. a reduction (an increase) in the tax of good $i$ is never (always) A-pro-poor if the good is a normal good; 
2. a reduction (an increase) in the tax of good $i$ is always (never) A-pro-poor if the good is an inferior good;

3. a reduction (an increase) in the tax of good $i$ is never (always) $R$-pro-poor if the good is a luxury good;

4. a reduction (an increase) in the tax of good $i$ is always (never) $R$-pro-poor if the good is a necessity.

The income elasticities $\varepsilon_{i}^{y}$ do not of course have to be uniformly negative, positive, or below or above 1 for all values of $y$. When elasticities are not so uniformly distributed, condition (24) will have to be checked on a case-by-case distributional basis.

The above results are also useful only in the cases in which only one tax or one price is changed, if for instance the government does not necessarily want to keep its overall revenue unchanged. For the case of a revenue-neutral tax reform scenario, one must finance a marginal tax reduction for a good $i$ by a marginal increase in the tax on a good $j$ in order to keep overall tax revenue constant. To show how to do this, suppose that there are $K$ consumption goods and denote by $R$ the per capita tax revenue of the overall indirect tax system:

$$
R(q)=\sum_{k=1}^{K} t_{k} X_{k}(q)
$$

The impact of the marginal tax reform on per capita tax revenue is then given by $d R$ :

$$
d R=\left[X_{i}(q)+\sum_{k=1}^{K} t_{k} \frac{\partial X_{k}(q)}{\partial t_{i}}\right] d t_{i}+\left[X_{j}(q)+\sum_{k=1}^{K} t_{k} \frac{\partial X_{k}(q)}{\partial t_{j}}\right] d t_{j}
$$

Revenue neutrality implies that $d R=0$. Using (26), this leads to:

$$
d t_{j}=-\gamma\left(\frac{X_{i}(q)}{X_{j}(q)}\right) d t_{i} \text { where } \gamma=\frac{1+\frac{1}{X_{i}(q)} \sum_{k=1}^{K} t_{k} \frac{\partial X_{k}(q)}{\partial t_{i}}}{1+\frac{1}{X_{j}(q)} \sum_{k=1}^{K} t_{k} \frac{\partial X_{k}(q)}{\partial t_{j}}} .
$$

Wildasin (1984) describes $\gamma$ as the efficiency cost ratio of obtaining one dollar of public funds by taxing good $j$ to subsidize good $i$. We can now state our second main result. 
Theorem 2 A marginal tax reduction on good $i$ financed by a marginal increase in the tax on good $j$ is $\eta$-pro-poor $(\eta \in\{A, R\})$ for all indices $P(z) \in \Pi^{s}(z)$ and for all poverty lines $z \in\left[0, z^{+}\right]$if and only if

$$
C D_{i}^{\eta: s}(z)-\gamma C D_{j}^{\eta: s}(z) \geq 0, \forall z \in\left[0, z^{+}\right] .
$$

The proof follows directly from that of Theorem 1 .

Yitzhaki and Thirsk (1990) and Yitzhaki and Slemrod (1991) find that if $\gamma$ is superior to one, it is impossible to secure a second-order welfare dominant tax reform due to the efficiency loss incurred. Makdissi and Wodon (2002) note, however, that from a poverty perspective, it is possible to have a reform that is dominant at all orders of stochastic dominance even when $\gamma$ is greater than one, so long as that part of the burden is supported by the non poor.

This is also true here in the context of $R$ and $A$ pro-poorness. In (28), it is the weighted difference between $C D_{i}^{\eta: s}(y)-\gamma C D_{j}^{\eta: s}(y)$ that matters. A tax reform can be economically inefficient (with $\gamma>1$ ) and still be considered to be pro-poor if $C D_{j}^{\eta: s}(y)$ is not too large compared to $C D_{i}^{\eta: s}(y)$.

When $s=1$ and when $\gamma=1$ (when there is no efficiency benefit or cost to the tax reform), a tax reform is absolutely pro-poor if the poor's share of the total consumption of good $i$ exceeds their share of the total consumption of good $j$. Exactly the same interpretation applies to the relative pro-poorness of a tax reform when $\gamma=1$ : the poor's share of the total consumption of good $i$ must exceed their share of the total consumption of good $j$. This is because mean real income is unaffected by a revenue-neutral tax reform when $\gamma=1 .^{[7}$

When $\gamma \neq 1$, the interpretation of $A$ and $R$ pro-poorness differs. Take $\gamma>1$, a case in which average real income falls after the tax reform (because of the efficiency cost). Relative pro-poorness demands that the share of the poor in total real income does not fall after the reform. Absolute pro-poorness demands that the absolute real income of the poor does not fall after the reform by more than the absolute fall in total real income. Since the initial share of the poor in total income is less than one $(y / \mu$ is less than one in (22)), an economically inefficient reform will be more likely to be absolutely pro-poor than relatively pro-poor.

The reverse reasoning applies to the case of an economically efficient tax reform, for which $\gamma<1$ and average real income increases. Relative pro-poorness demands that the share of the poor in total real income increases after the reform, and absolute pro-poorness will require that the absolute real income of the poor

\footnotetext{
${ }^{7}$ When $\gamma=1$, we have $g=a=0$ since $X_{j} d t_{j}+X_{i} d t_{i}=0$.
} 
increases by more than total real income after the reform. Because of this, an economically efficient reform will be more likely to be relatively pro-poor than absolutely pro-poor.

If $\gamma<1$, a reform will also be more likely to be considered relatively propoor than absolutely pro-poor as $s$ increases. The converse holds if $\gamma>1$. This is because the greater the value of $s$, the greater the importance given to the poorest of the poor in assessing pro-poorness conditions. (20) and (21) show that the standard in assessing relative pro-poorness is the difference between shares in the consumption of a good and shares in total income, but that the standard in assessing absolute pro-poorness is the difference between shares in the consumption of a good and 1. For the poor, that difference for relative pro-poorness will be larger than for absolute pro-poorness. Since an increase in $s$ increases the importance given to the poorer individuals, ceteris paribus, an increase in $s$ will also lead more quickly to the validation of (28) for $\eta=R$ than for $\eta=A$ if $\gamma<1$, and more quickly to the validation of (28) for $\eta=A$ than for $\eta=R$ if $\gamma>1$. If $\gamma=1$ this difference vanishes as the conditions for relative or absolute pro-poorness of tax reforms become both equivalent to the condition that a tax reform reduces poverty (see Duclos, Makdissi, and Wodon 2008).

\section{Estimation and inference}

To be able to implement empirically the above tools, we ought to consider the estimation and the sampling distribution of the curves needed to test for propoorness. For this, we suppose for expositional simplicity that we dispose of a sample of $N$ independently and identically distributed observations, ${ }^{8}$ and that the pre-reform income and consumption of goods $j$ and $l$ for observation $i$ ( $i=$ $1, \ldots, N)$ are denoted by $y_{i}, x_{j}^{i}$ and $x_{l}^{i}$, respectively. Ignoring the constant $\frac{1}{(s-2) !}$, the $C D^{\eta: s}$ curves can then be estimated for $s \geq 2$ by the natural estimators

$$
\widehat{C D}_{k}^{R: s}(z)=\frac{\frac{1}{N} \sum_{i=1}^{N} x_{k}^{i}\left(z-y_{i}\right)_{+}^{s-2}}{\widehat{X}_{k}}-\frac{\frac{1}{N} \sum_{i=1}^{N} y_{i}\left(z-y_{i}\right)_{+}^{s-2}}{\widehat{\mu}}
$$

\footnotetext{
${ }^{8}$ The analytical results can be extended to account for complex multi-stage sampling designs. Taking into sampling design is indeed done in the Mexican illustration below, using analytical asymptotic methods similar to those described in Duclos and Araar (2006), Chapter 16.
} 
and

$$
\widehat{C D}_{k}^{A: s}(z)=\frac{\frac{1}{N} \sum_{i=1}^{N} x_{k}^{i}\left(z-y_{i}\right)_{+}^{s-2}}{\widehat{X}_{k}}-\frac{1}{N} \sum_{i=1}^{N}\left(z-y_{i}\right)_{+}^{s-2},
$$

where $f_{+}=\max (0, f), \widehat{X}_{k}=\frac{1}{N} \sum_{i=1}^{N} x_{k}^{i}$ is an estimator of average consumption of good $k$, and $\widehat{\mu}=\frac{1}{N} \sum_{\eta: s}^{N} y_{i=1}^{i}$ is an estimator of average income.

The estimators $\widehat{C D}_{l}^{\eta: s}(z)-\gamma \widehat{C D}_{j}^{\eta: s}(z)$ are given analogously. Let $C D^{s}\left(x_{k} ; z\right)=$ $\int_{0}^{z} x_{k}(y, q)(z-y)^{s-2} d F(y)$ and $\widehat{C D}^{s}\left(x_{k} ; z\right)=\frac{1}{N} \sum_{i=1}^{N} x_{k}^{i}\left(z-y_{i}\right)_{+}^{s-2}$. The asymptotic sampling distribution of $\widehat{C D}^{s}\left(x_{k} ; z\right)$ for $s \geq 2$ is given in Theorem 3 .

Theorem 3 Let the second population moment of $x_{k}(y, \theta)(z-y)_{+}^{s-2}$ be finite. Then, for $s \geq 2, N^{0.5}\left(\widehat{C D}^{s}\left(x_{k} ; z\right)-C D^{s}\left(x_{k} ; z\right)\right)$ is asymptotically normal with mean zero and with asymptotic variance given by:

$$
\begin{aligned}
& \lim _{N \rightarrow \infty} N \cdot \operatorname{var}\left(\widehat{C D}^{s}\left(x_{k} ; z\right)-C D^{s}\left(x_{k} ; z\right)\right) \\
= & (s-2) !^{-2} \int\left(x_{k}(y)(z-y)_{+}^{s-2}\right)^{2} d F(y)-C D^{s}\left(x_{k} ; z\right)^{2} .
\end{aligned}
$$

Prof: See the appendix.

The asymptotic distribution of $\widehat{C D}_{k}^{R: s}(z)$ and $\widehat{C D}_{k}^{A: s}(z)$ can be obtained by noting that (29) and (30) are functions of $\widehat{C D}^{s}\left(x_{k} ; z\right), \widehat{X}_{k}, \widehat{C D}^{s}(y ; z), \widehat{\mu}$, and $\widehat{C D}^{s}(1 ; z)$. The sampling distribution $\widehat{C D}^{s}(y ; z)$ and $\widehat{C D}^{s}(1 ; z)$ can be obtained as special cases of Theorem 3 , $\widehat{\mu}$ and $\widehat{X}_{k}$ are simple sums of independently and identically distributed random variables. Using the "delta method" of Rao (1973), the sampling distribution of $\widehat{C D}_{k}^{A: s}(z)$ and $\widehat{C D}_{k}^{R: s}(z)$ can then be obtained by a linear transformation of the covariance matrix of $\widehat{C D}^{s}\left(x_{k} ; z\right), \widehat{X}_{k}, \widehat{C D}^{s}(y ; z), \widehat{\mu}$, and $\widehat{C D}^{s}(1 ; z)$.

For $s=1$, we need an estimator of $x_{k}(z, q)$, the expected consumption of good $k$ at $z$, times $f(z)$. For this, we can use a non-parametric estimation procedure, using for instance a kernel estimator defined such as

$$
\widehat{C D}^{1}\left(x_{k} ; z\right)=\frac{1}{N} \sum_{i=1}^{N} \kappa_{h}\left(z-y_{i}\right) x_{k}^{i}
$$


where $h$ is a kernel bandwidth, $\kappa_{h}(u)=h^{-1} \kappa(u / h), \int \kappa(u) d u=1, \int u \kappa(u) d u=$ 0 (for symmetry), and $\int u^{2} \kappa(u) d u=c_{\kappa}$. In the illustration below, we choose a Gaussian form for $\kappa(u)$,

$$
\kappa(u)=\frac{e^{-0.5 u^{2}}}{\sqrt{2 \pi}},
$$

but other kernel functional forms could also be used. In the illustration, we choose $h$ using the cross-validation method, which is asymptotically optimal (see Härdle 1990, Theorem 5.1.1) and we also a locally linear estimator to avoid biases at the lower bound of expenditures. Theorem 4 then gives the asymptotic sampling distribution of $\widehat{C D}^{1}\left(x_{k} ; z\right)$.

Theorem 4 Let i) $\int \kappa(u)^{2} d u$ exists, ii) $h \sim N^{-0.2}$, iii) $C D_{k}^{1}(y)$ be twice differentiable in $y$ at $y=z$, iv) $f(z)>0$, and $v) c_{k}(z)=x_{k}(z)^{2}$ be continuous at $z$. Then, $(N h)^{0.5}\left(\widehat{C D}^{1}\left(x_{k} ; z\right)-C D^{1}\left(x_{k} ; z\right)-h^{2} B_{k}(z)\right)$ is asymptotically normal with mean 0 and limiting variance $V_{k}(z)$, where $B_{k}(z)=0.5 c_{\kappa} \partial^{2} C D^{1}\left(x_{k} ; z\right) /(\partial z)^{2}$ and $V_{k}(z)=f(z) c_{k}(z) \int \kappa(u)^{2} d u$.

Prof: See the appendix.

The sampling distribution of $\widehat{C D}_{k}^{R: 1}(z)$ and $\widehat{C D}_{k}^{A: 1}(z)$ can then be obtained by a linear transformation of the covariance matrix of $\widehat{C D}^{1}\left(x_{k} ; z\right), \widehat{X}_{k}$ and $\widehat{\mu}$ using the delta method. As for $s \geq 2$, the terms needed to carry out statistical inference are either constants $\left(c_{\kappa}\right.$ and $\left.\int \kappa(u)^{2} d u\right)$ or can be readily estimated consistently in a distribution-free manner (this is the case, for instance, of $\int\left(x_{k}(z-y)_{+}^{s-2}\right)^{2} d F(y), \widehat{C D}^{s}\left(x_{k} ; z\right)^{2}, \partial^{2} C D^{1}\left(x_{k} ; z\right) /(\partial z)^{2}, f(z)$ and $\left.c_{k}(z)\right)$. Note, however, that it is usual to consider (and to find) the bias terms $B_{k}(z)$ and $B_{k}(z) / X_{k}$ to be of negligible practical importance ${ }^{9}$, and we also make this assumption in the illustration below.

\section{An application to Mexico's indirect tax system}

\subsection{Mexican data}

We now briefly apply the above methodology to Mexico's indirect tax system. The data used for our application comes from the National Income and Expendi-

\footnotetext{
${ }^{9}$ This is particularly true in the study of consumption data, where the second order derivative of expected consumption at $z, \partial^{2} C D^{1}\left(x_{k} ; z\right) /(\partial z)^{2}$, may be expected to be small. For more on this, see for instance Härdle (1990), p.101.
} 
ture (ENIGH) Survey collected in 2004, which is nationally representative of the Mexican population. ENIGH surveys collect information on incomes and expenditures, goods and services used for self-consumption, as well as socio-economic characteristics and labor market activities of all household members.

As is common in Latin America, we use total income per capita as the measure of living standards for all members of a household. To correct for spatial variation in prices, we assess all incomes in reference to rural prices and multiply urban household incomes by the ratio of rural to urban poverty lines. We use as a guide a 2004 rural poverty line set to 550 pesos per month per capita. To simplify the interpretation of figures and the discussion, we normalize income by that rural poverty line so that a household with an income equal to one is at the level of the rural poverty line and a household with an income of 2 has a real income equal to twice that line. We weight households by the product of household size and household sampling weight; this is equivalent to formulating our estimators on the basis of the population of individual living standards.

We consider indirect tax reforms affecting four broad classes of goods and services (food, energy, transport and other goods) as well as various foodstuffs. 10 Table 1 presents the percentage of total expenditure allocated to goods and services by quintile. As expected, the share of total expenditures on food items decreases from the poorest to the richest quintile. Conversely, the share of total expenditures on transportation and other goods increases with quintiles. Table 1 also shows that the composition of the food basket varies with income quintiles; households in the poorest income quintile spend a greater share of their total food expenditure on cereals $(25.88 \%)$ and on vegetables $(19.30 \%)$ than those in the richest quintile - who spend relatively more $(46.44 \%)$ on protein-intensive foods (milk, meat and fish).

\subsection{Impact of tax changes}

Figure 1 presents relative dominance curves $C D^{R: s}(z)$ for three broad classes of goods and services and for $s=1,2$, along with two-sided $90 \%$ confidence intervals. Using the results of Theorem 1 , this shows that a marginal tax reduction on Food or on Energy would be relatively pro-poor, and that this conclusion would be valid for any relative pro-poor judgements based on indices $P \in \Pi^{1}(z)$ (namely, those that in agreement with the Pen principle) for a wide range of poverty lines

\footnotetext{
${ }^{10}$ In 2004, all foodstuffs were exempt of value-added taxes (VAT) in Mexico. A few of these goods were subsidized, however.
} 
reaching almost 3 . For $s=2$, this is true for all possible poverty lines. Conversely, a marginal increase in the tax on any of these two classes of goods would be considered relatively "anti-poor". This suggests that it is important to consider the use to which increases in tax revenues are put to know whether a tax reform is globally pro-poor or not. We return to this below.

Figure 2 presents the corresponding absolute dominance curves $C D^{A: s}(z)$ for three broad classes of goods and services. A marginal reduction in taxes on any of the different goods could not be considered to be absolutely pro-poor. As indicated in Corollary 1, this result is not surprising considering the fact that the absolute pro-poor requirements are typically more demanding (since most goods are normal goods) than the relative ones (since not all normal goods are luxury goods) in the case of tax decreases. Conversely, increases in taxes on any of the different goods will be absolutely pro-poor for all $P \in \Pi^{1}(z)$ for a large range of poverty lines and for all $P \in \Pi^{2}(z)$ for all poverty lines. 11

\subsection{Impact of efficiency-neutral tax reforms}

We now turn to the pro-poorness of revenue-neutral tax reforms. We first assume that the tax reforms are efficiency neutral, $v i z$, that $\gamma=1$. Recall from page 11 that with $\gamma=1$ the tests for absolute and relative pro-poorness are equivalent.

\subsubsection{Efficiency-neutral reforms involving broad classes of goods}

Figure 3 presents the difference between the absolute pro-poor consumption dominance curves of Food and Transport, and this, for first and second orders of dominance. Except for rather low poverty lines, the lower bound of the confidence interval of this difference is always greater than zero, and hence a revenue-neutral tax reform that decreases food taxes and increases transportation taxes would be considered absolutely and relatively pro-poor for all $P \in \Pi^{1}(z)$ for a range of poverty lines extending to about 3 , and for all $P \in \Pi^{2}(z)$ for all poverty lines, except again for a bottom range of relatively small poverty lines.

Figure 4 presents a similar difference, but this time between Food and Energy. For $s=1$, the lower bound of the confidence interval is greater than zero only up

\footnotetext{
${ }^{11}$ Theoretically speaking, the dominance tests carried out in Section 4 must be applied over ranges varying between 0 and some $z^{+}$. Statistically speaking, however, there is a general "information-less" problem in the tails of distributions that impedes such testing for values of $z$ close to 0 . Hence, statistically speaking, we must restrict the tests to a range that is lower-bounded somewhere above 0. See Davidson and Duclos (2006) for a discussion of this.
} 
to about the official poverty line. Given this degree of statistical insignificance, it is therefore not immediate that one should consider as first-order pro-poor a revenue and efficiency neutral tax reform that decreases food taxation and increases energy taxation - or indeed the reverse. The concern is alleviated if we move to $s=2$ : the lower bound of the confidence interval is greater than zero after around $z=0.4$ and up to almost 3 .

Such tests of the effect of revenue and efficiency neutral tax reforms can be performed on every pair of goods. Table 2 summarizes the test results for the pairs of the three main goods. Here are some of the main findings.

- A tax reform that were to increase taxation on Transport and decrease taxation on Food would be absolutely and relatively first-order pro-poor over a wide range of poverty lines $(0.145-3$ for the estimates, $0.190-2.971$ for the statistically significant range) $\frac{12}{}$

- A tax reform that were to increase taxation on Transport and decrease taxation on Energy would also be absolutely and relatively first-order pro-poor over a wide range of poverty lines (0.137-3 for the estimates, 0.211-2.953 for the statistically significant range).

- Applying statistical inference techniques can alter conclusions substantially. For instance, the estimates of Table 2 suggest that a tax reform that increases taxes on Energy and that decreases taxes on Food is pro-poor over a wide range of poverty lines ( 0.15 to 2.711$)$. This is considerably shortened $(0.206$ to 0.925 ) when one focusses on the range over which the ranking of the curves is statistically significant.

- If a reform is first-order pro-poor over a range of poverty lines that starts at 0 , then that range widens as we move to second-order pro-poorness see for instance the estimates shown in the first column, where the range of poverty lines over which a rise in Food taxes combined to a fall in Energy taxes is pro-poor increases from $0-0.15$ to $0-0.31$ as we move from first to second-order dominance.

\footnotetext{
${ }^{12}$ Note that the poverty headcount at $z=0.145$ is around $0.3 \%$. Very little statistical information is thus available below that value, an indication of the information-less problem mentioned in footnote 11. It would also require a pro-poor judgement that would be almost strictly Rawlsian to reverse the pro-poor judgements implied by the tests over $0.145-3$ and $0.190-2.971$.
} 
- This last result, however, is true only when the ranking is valid for a firstorder range of poverty lines that right at 0 . Table 2 shows alternative instances of interesting relationships between the ranges over which firstorder and second-order dominance hold. For instance, an increase in Energy taxes and a fall in Food taxes (third column) is statistically first-order propoor over a range $0.206-0.925$ of poverty lines; that range becomes 0.383 2.753 for second-order dominance. Increasing the order of dominance thus reduces statistical significance over the lower values of poverty lines (the lower bound increases from 0.206 to 0.383 ), but it increases considerably (from 0.925 to 2.753 ) the upper bound of poverty lines over which the ranking of the curves is statistically significant.

\subsubsection{Efficiency-neutral reforms involving foodstuffs}

Let us now turn to the pro-poorness of revenue and efficiency neutral tax reforms involving solely food items. Figure 5 shows for instance the difference between the pro-poor consumption dominance curve of Cereals and that of Vegetables for first and second orders. The results are not statistically significant. Moreover, and as discussed above, when a reform is not statistically pro-poor within a range of poverty lines that starts at 0 , the statistically insignificant range can tend to widen as $s$ is increased. This can be seen in Figure 5 by noting that the area over which the confidence intervals overlap with the 0 line is pushed up and is wider with second-order than with first-order dominance.

The pro-poorness results involving the pairs of the three main food items are summarized in Table 3. They indicate that increasing Mexican taxes on Milk, meat and fish to decrease taxes on Cereals and/or on Vegetables would be pro-poor, both in terms of normative robustness and in terms of statistical significance, and this, whether we consider first or second-order dominance. The results of Table 3 also show that reforms involving any other combination of food items would not be so robustly pro-poor.

\subsection{Impact of efficiency non-neutral tax reforms}

We have assumed until now that tax reforms would be efficiency neutral. This assumes that the marginal deadweight loss of indirect taxation per dollar of tax raised is the same across all commodities. This is unlikely to hold since it im-

plicitly assumes that compensated price elasticities are the same across all of the goods involved in the reform. 
To allow for efficiency non-neutral tax reforms, assume to start with that $\gamma=2$ - that is, that tax reforms are inefficient to the extent that each per capita dollar of tax raised on good $j$ to finance a tax decrease on good $i$ (see (28)) decreases per capita welfare by 1 (namely, by $\gamma-1$ ) dollar. Figure 6 shows the difference between the first-order absolute and relative pro-poor consumption dominance curves of Food and of Energy, when the dominance curve for Energy is weighted by $\gamma=2$. Setting $\gamma=2$ in that way implicitly supposes that the compensated price elasticity for Food is lower than that for Energy, and that the marginal deadweight loss from taxing Energy is thus greater than that from taxing Food.

Recall from Figure 4 that the difference between the first-order pro-poor consumption dominance curves of Food and of Energy was statistically positive only over a small range of poverty lines when $\gamma$ was set to 1 . With $\gamma=2$, Figure 6 shows that the difference in the absolute curves is now nowhere positive. It is even in fact negative between around 0.7 and 2.2, which means that it would now be relatively pro-poor over that range of poverty lines to decrease Energy taxes and increase Food taxes.

The more inefficient it is to tax a good, the greater the tax rate that must be levied on that good to generate the tax revenues needed to decrease taxes on another, less price-elastic, good. If the more price-elastic good is not a luxury good, this makes the poor lose proportionately more from an inefficient tax reform than under an efficiency-neutral tax reform. This also makes increasing the price of the more price-elastic good less likely to be relatively pro-poor. Only when the price-elastic good is also a luxury good will an increase in its tax be conducive to greater relative pro-poorness. Since Energy is not a luxury good in Mexico, the greater the deadweight loss associated to taxing Energy, the more relatively propoor it will be to tax Food instead. This is true even though, as shown on Figure 1. Food may be less income elastic than Energy in Mexico.

Figure 6 also shows that the difference in the absolute consumption dominance curves is now everywhere positive, which also means that it is now absolutely propoor to tax Energy to finance a tax decrease on Food. The reverse also holds: it would absolutely anti-poor to finance a tax decrease on Energy by raising taxes on Food. This is in sharp contrast to the above results for relative pro-poorness. If the price elastic good is a normal good, the distance between the absolute loss of the rich and that of the poor for $\gamma>1$ will be even more considerable than with an efficiency-neutral tax reform. Absolute pro-poorness of increasing taxes on the more price-elastic good is then also more likely to hold in that context.

A similar exercise is repeated in Figure 7, which shows the difference between the first-order relative and absolute pro-poor consumption dominance curve for 
Cereals and that for Vegetables. The curve for Vegetables (presumably the more price-elastic good) is being weighted by $\gamma=2$. This can be compared to Figure 5 in which $\gamma=1$. With $\gamma=2$, it now possible to declare that a revenue-neutral reform that increases taxes on Cereals and decreases them on Vegetables is firstorder relatively pro-poor. The reasoning is the same as before: Vegetables are not a luxury good, and it is thus better not to raise taxes on that price-elastic good. But a revenue-neutral reform that decreases taxes on Cereals and increases them on Vegetables would be first-order absolutely pro-poor over a wide range of poverty lines, again because, for $\gamma>1$, that would maximize the distance between the absolute loss of the rich and that of the poor.

\subsection{Trading off efficiency and distribution}

The trade-off between efficiency (which is related to price elasticities) and the shape of the $C D$ curves (which is related to income elasticities) can be usefully exemplified by the following ratio $\delta_{i, j}^{\eta: s}(z)$ of $C D$ curves:

$$
\delta_{i, j}^{\eta: s}(z)=\frac{C D_{i}^{\eta: s}(z)}{C D_{j}^{\eta: s}(z)} .
$$

Using (28) and supposing that $C D_{j}^{\eta: s}(z)>0$, we then find that a revenue-neutral tax reform that reduces taxation on good $i$ and increases taxation on good $j$ is $\eta$-pro-poor $(\eta \in\{A, R\})$ if and only if

$$
\delta_{i, j}^{\eta: s}(z) \geq \gamma_{i, j} \forall z \in\left[0, z^{+}\right]
$$

where $\gamma_{i, j}$ is the efficiency cost of taxing good $j$ relative to $\operatorname{good} i$. If $C D_{j}^{\eta: s}(z)<$ 0 , then the condition is rather that

$$
\delta_{i, j}^{\eta: s}(z) \leq \gamma_{i, j} \forall z \in\left[0, z^{+}\right] .
$$

When $C D_{j}^{\eta: s}(z)>0$, condition (35) shows that we can interpret $\delta_{i, j}^{\eta: s}(z)$ as those critical efficiency ratios that must not be exceeded by $\gamma_{i, j}$ for a tax reform that reduces taxation on good $i$ (and increases taxation on good $j$ ) to be declared pro-poor. A reverse use of $\delta_{i, j}^{\eta: s}(z)$ can also be made: we can interpret $\delta_{i, j}^{\eta: s}(z)$ as the critical efficiency ratios that must be surpassed by $\gamma_{i, j}$ for a tax reform that reduces taxation on good $j$ (and increases taxation on good $i$ ) to be declared propoor. When $C D_{j}^{\eta: s}(z)<0$, condition (36) shows that we can interpret $\delta_{i, j}^{\eta: s}(z)$ as critical efficiency ratios that must be exceeded by $\gamma_{i, j}$ for a tax reform that reduces taxation on good $i$ (and increases taxation on good $j$ ) to be declared pro-poor. 
Figure 8 shows the $\delta^{\eta: s}(z)$ curves for a reform involving Food and Energy. Let us set an upper bound $z^{+}=2$ to the range of poverty lines. Consider first the absolute pro-poorness of a revenue-neutral reform that decreases taxation on Food and increases taxation on Energy. Since $C D_{\text {Energy }}^{A: s}(z)<0$ (see Figure 2), for such a reform to be absolutely pro-poor according to Figure 8 , the efficiency cost $\gamma_{i, j}$ of taxing energy relative to food must be larger than 1.7. This statistic is given by the maximal height of the upper bound of the confidence intervals shown in Figure 8 . At that maximal height, $\gamma_{i, j}$ is indeed statistically greater than $\delta_{i, j}^{\eta: s}(z)$, and condition (36) is therefore statistically verified. With $\gamma_{i, j}$ larger than 1.7 , the absolute fall in average real income will always be larger than the fall in the poor's real income, no matter what value of $z$ below 2 is selected. This is because a $\gamma_{i, j}$ larger than 1.7 will always involve a sufficiently large increase in the tax on Energy to compensate for the effect of the fall in Food taxation.

Consider then a revenue-neutral reform that increases taxation on food and decreases taxation on energy, for the same upper bound of $z^{+}=2$. For such a reform to be absolutely pro-poor according to Figure 8 , the efficiency cost $\gamma_{i, j}$ of taxing energy relative to food must be lower than 0.79 . This statistic is now given by the minimal height of the lower bound of the confidence intervals, for reasons that are the reverse of those just mentioned.

A similar exercise can be carried out for relative pro-poorness, but with quite different results. Since we now have that $C D_{\text {Energy }}^{R: s}(z)>0$ (see Figure 1), the condition to check is (35). A revenue-neutral reform that decreases taxation on Food and increases taxation on Energy will be relatively pro-poor according to Figure 8 if the efficiency cost $\gamma_{i, j}$ of taxing energy relative to food is lower than around 0.5. Conversely, a revenue-neutral reform that increases taxation on Food and decreases taxation on Energy will be relatively pro-poor if the efficiency cost $\gamma_{i, j}$ of taxing energy relative to food is greater than 4.5. When $0.5 \leq \gamma_{i, j} \leq 4.5$, the effect on relative pro-poorness of a tax reform involving Food and Energy is either statistically insignificant or normatively sensitive to the choice of indices and poverty lines between 0 and 2 .

\section{Conclusion}

This paper develops a methodology for checking wether indirect tax reforms can be considered to be pro-poor or not. The methodology extends previous stochastic dominance techniques and enables one to characterize tax reforms on the basis of wide spectra of possible views of "pro-poorness". This is done for 
both absolute and relative pro-poorness, for ranges of possible poverty lines, and for different degrees of distributional sensitivity to the differentiated impact of tax reforms across pre-reform values of welfare. Statistical inference techniques are also provided to make these tools empirically applicable.

The methodology is applied to the pro-poorness of possible reforms of Mexico's indirect tax system, both across broad classes of goods and across foodstuffs. This leads to the characterizations of a number of possible pro-poor indirect tax reforms. The results also show that whether indirect tax reforms can be deemed to be pro-poor can depend to an important extent on the type of distributional and/or pro-poor views that are applied to the analysis, and that it is therefore important to make such views clear when making policy recommendations for pro-poor tax reforms. The results further indicate that whether indirect tax reforms are propoor depends 1) on whether government revenue neutrality is maintained, and 2) on the size of the deadweight gains/losses incurred in the trade-off between balancing efficiency and redistribution.

\section{Appendix}

\subsection{Proof of Theorem 1}

First note that, substituting (20) in (18) and (21 in (19), we obtain

$$
\frac{\partial P^{* \eta}(z)}{\partial t_{i}}=-X_{i}(q) \int_{0}^{\infty} p^{(1)}(y, z) C D_{i}^{\eta: 1}(y) d y .
$$

The sufficiency condition for $s=1$ is proved from (37) by noting that $p^{(1)}(y, z)$ is negative. We then need to integrate by parts $\int_{0}^{\infty} p^{(1)}(y, z) C D_{i}^{\eta: 1}(y) d y$,

$$
\begin{aligned}
\int_{0}^{\infty} p^{(1)}(y, z) C D_{i}^{\eta: 1}(y) d y= & \left.p^{(1)}(y, z) C D_{i}^{\eta: 2}(y)\right|_{0} ^{\infty} \\
& -\int_{0}^{\infty} p^{(2)}(y, z) C D_{i}^{\eta: 2}(y) d y
\end{aligned}
$$

We know that $C D_{i}^{\eta: 2}(0)=0$ and that $p^{1}(\infty, z)=0$. The first term on the r.h.s. of the above is thus nil. Consequently, equation (38) may be rewritten as

$$
\int_{0}^{\infty} p^{(1)}(y, z) C D_{i}^{\eta: 1}(y) d y=-\int_{0}^{\infty} p^{(2)}(y, z) C D_{i}^{\eta: 2}(y) d y .
$$


Now, assume that we have:

$$
\int_{0}^{\infty} p^{(1)}(y, z) C D_{i}^{\eta: 1}(y) d y=(-1)^{s-2} \int_{0}^{\infty} p^{(s-1)}(y, z) C D_{i}^{\eta: s-1}(y) d y .
$$

Integrating by parts equation (40), we get

$$
\begin{aligned}
\int_{0}^{\infty} p^{(1)}(y, z) C D_{i}^{\eta: 1}(y) d y= & \left.(-1)^{s-2} p^{(s-1)}(y, z) C D_{i}^{\eta: s-1}(y)\right|_{0} ^{\infty} \\
& -(-1)^{s-2} \int_{0}^{\infty} p^{(s)}(y, z) C D_{i}^{\eta: s}(y) d y .
\end{aligned}
$$

$C D_{i}^{\eta: s}(0)=0$ and $p^{(s-1)}(\infty, z)=0$ is implied by the definition of $\infty$ and by (2). We can rewrite (41) as

$$
\int_{0}^{\infty} p^{(1)}(y, z) C D_{i}^{\eta: 1}(y) d y=(-1)^{s-1} \int_{0}^{\infty} p^{(s)}(y, z) C D_{i}^{\eta: s}(y) d y .
$$

Equation (39) obeys the relation depicted in (40). We have shown that if (40) is true then equation (42) is also true. This implies that equation (42) is true for all integer $s \in\{2,3, \ldots, s-1\}$. From equation (37) and (42), we get

$$
\frac{\partial P^{* \eta}(z)}{\partial t_{i}}=(-1)^{s} X_{i}(q) \int_{0}^{\infty} p^{(s)}(y, z) C D_{i}^{\eta: s}(y) d y .
$$

This last equation together with equation (2) proves the sufficiency of the condition.

In order to establish necessity, consider the set of functions $p(y, z)$ for which the $(s-1)$ th derivative (with $p^{(0)}(y, z)=p(y, z)$ ) is of the following form

$$
p^{(s-1)}(y, z)=\left\{\begin{array}{cc}
(-1)^{s-1} \epsilon & y \leq \bar{y} \\
(-1)^{s-1}(\bar{y}+\epsilon-y) & \bar{y}<y \leq \bar{y}+\epsilon \\
0 & y>\bar{y}+\epsilon .
\end{array}\right.
$$

Poverty indices whose function $p(y, z)$ has the particular above form for $p^{(s-1)}(y, z)$ belong to $\Pi^{s}$. This yields:

$$
p^{(s)}(y, z)=\left\{\begin{array}{cc}
0 & y<\bar{y} \\
(-1)^{s} & \bar{y}<y<\bar{y}+\epsilon \\
0 & \bar{y}>\bar{y}+\epsilon .
\end{array}\right.
$$

Imagine now that $C D_{i}^{\eta: s}(y)<0$ on an interval $[\bar{y}, \bar{y}+\epsilon]$ for $\bar{y}<z^{+}$and for $\epsilon$ that can be arbitrarily close to 0 . For $p(y, z)$ defined as in (44), expression (43) is then positive and the marginal tax reform induces a marginal increase of poverty. Hence, it cannot be that $C D_{i}^{\eta: s}(y)<0$ for $y \in[\bar{y}, \bar{y}+\epsilon]$ when $\bar{y}<z^{+}$. This proves the necessity of the condition. 


\subsection{Proof of Theorem 3}

$\widehat{C D}^{s}\left(x_{k} ; z\right)$ is a consistent estimator of $C D^{s}\left(x_{k} ; z\right)$ by the existence of the first population moment of $x_{k}(y)(z-y)_{+}^{s-2}$ and the law of large numbers. $\widehat{C D}^{s}\left(x_{k} ; z\right)$ is $N^{0.5}$ consistent and asymptotically normal by the existence of the second population moment and the central limit theorem, with asymptotic variance given by 31 by simple calculation.

\subsection{Proof of Theorem 4}

Note first that $E\left[\widehat{C D}^{1}\left(x_{k} ; z\right)\right]=\int \kappa_{h}(z-y) x_{k}(y) f(y) d y$. Denoting $t=$ $h^{-1}(z-y)$ and expanding around $t_{0}=0$, for small $h$ this is approximately equal to

$$
\begin{aligned}
& E\left[\widehat{C D}^{1}\left(x_{k} ; z\right)\right] \\
\simeq & \int \kappa(t)\left[C D^{1}\left(x_{k} ; z\right)-t h C D^{1 \prime}\left(x_{k} ; z\right)(z)+0.5 t^{2} h^{2} \widehat{C D}^{1 \prime \prime}\left(x_{k} ; z\right)(z)\right] d t \\
= & +0.5 h^{2} \widehat{C D}^{1 \prime \prime}\left(x_{k} ; z\right)(z) c_{\kappa}
\end{aligned}
$$

since $\int \kappa(u) d u=1, \int u \kappa(u) d u=0$, and $\int u^{2} \kappa(u) d u=c_{\kappa}$. Hence, the bias $E\left[\widehat{C D}^{1}\left(x_{k} ; z\right)\right]-C D^{1}\left(x_{k} ; z\right)$ is given by $0.5 h^{2} \widehat{C D}^{1 \prime}\left(x_{k} ; z\right) c_{\kappa}$.

By (32), note that $\widehat{C D}^{1}\left(x_{k} ; z\right)$ is a sum of iid variables to which we may apply the central limit theorem and show asymptotic normality. We also have that

$$
\begin{aligned}
& N \operatorname{var}\left(\widehat{C D}^{1}\left(x_{k} ; z\right)\right) \\
= & \operatorname{var}\left(\kappa_{h}(z-y) x_{k}(y)\right)=E\left[\kappa_{h}(z-y)^{2}\left(x_{k}(y)\right)^{2}\right]-E\left[\widehat{C D}^{1}\left(x_{k} ; z\right)\right]^{2} \\
= & \int_{y} \kappa_{h}(z-y)^{2}\left(x_{k}(y)\right)^{2} d F(y)-E\left[\widehat{C D}^{1}\left(x_{k} ; z\right)\right]^{2} \\
= & \int_{u} h^{-2} \kappa(u)^{2}\left(x_{k}(z-u h)\right)^{2} d F(z-u h)-E\left[\widehat{C D}^{1}\left(x_{k} ; z\right)\right]^{2}
\end{aligned}
$$

where the last expression is obtained by substituting $u$ for $h^{-1}(z-y)$. For small 
$h,(48)$ is approximately equal to

$$
\begin{aligned}
& N \operatorname{var}\left(\widehat{C D}^{1}\left(x_{k} ; z\right)\right) \\
\cong & \int_{u} h^{-1} \kappa(u)^{2}\left(x_{k}(z)\right)^{2} f(z) d u-E\left[\widehat{C D}^{1}\left(x_{k} ; z\right)\right]^{2} \\
= & h^{-1} f(z)\left(x_{k}(z)\right)^{2} \int_{u} \kappa(u)^{2} d u-E\left[\widehat{C D}^{1}\left(x_{k} ; z\right)\right]^{2} \\
\cong & h^{-1} f(z)\left(x_{k}(z)\right)^{2} \int_{u} \kappa(u)^{2} d u \\
= & h^{-1} f(z) c_{k}(z) \int \kappa(u)^{2} d u .
\end{aligned}
$$

Hence,

$$
\begin{aligned}
& \lim _{N \rightarrow \infty} \operatorname{Nhvar}\left(\widehat{C D}^{1}\left(x_{k} ; z\right)-C D^{1}\left(x_{k} ; z\right)-h^{2} B_{k}\right) \\
= & f(z) c_{k}(z) \int \kappa(u)^{2} d u=V_{k}(z),
\end{aligned}
$$

which concludes the proof.

\section{References}

AhMAD, E. AND N. STERN (1984): “The Theory of Reform and Indian Indirect Taxes," Journal of Public Economics, 25, 259-98.

AraAr, A., J.-Y. Duclos, M. Audet, AND P. MAKdissi (2007): "Has Mexican growth been pro-poor?” Tech. rep., Université Laval.

Besley, T. And R. Kanbur (1988): "Food Subsidies and Poverty Alleviation," The Economic Journal, 98, 701-719.

BourguignON, F. (2003): “The poverty-growth-inequality triangle,” Tech. rep., Paris, Agence française de développement.

BRuno, M., M. RaVALLION, AND L. SQuiRe (1998): "Equity and Growth in Developing Countries: Old and New Perspectives on the Policy Issues," in Income Distribution and High-Quality Growth, ed. by V. Tanzi and K. C. (eds.), Cambridge: MIT Press. 
Chakravarty, S. (1983): "Ethically Flexible Measures of Poverty," Canadian Journal of Economics, XVI, 74-85.

Clark, S., R. Hemming, AND D. Ulph (1981): “On Indices for the Measurement of Poverty," The Economic Journal, 91, 515-526.

DAVIDSON, R. AND J.-Y. DuClOS (2006): “Testing for Restricted Stochastic Dominance," IZA Discussion Paper No 2047, IZA.

Dollar, D. AND A. KRAAY (2002): "Growth Is Good for the Poor," Journal of Economic Growth, 7, 195-225.

DuClos, J.-Y. (2009): "What is "Pro-Poor"?" Social Choice and Welfare, $32,37-58$.

Duclos, J.-Y. AND A. ArAar (2006): Poverty and Equity Measurement, Policy, and Estimation with DAD, Berlin and Ottawa: Springer and IDRC.

Duclos, J.-Y. AND P. MAKDISSI (2003): "Restricted and Unrestricted Dominance for Welfare, Inequality and Poverty Orderings," Journal of Public Economic Theory, 6, 145-164.

Duclos, J.-Y., P. MAKdissi, AND Q. Wodon (2008): "SociallyImproving Tax Reforms," International Economic Review, 49, 15071539.

Eastwood, R. And M. Lipton (2001): "Pro-poor Growth and ProGrowth Poverty Reduction: What do they Mean? What does the Evidence Mean? What can Policymakers do?" Asian Development Review, 19, 1-37.

EsSAMA-NsSAH, B. (2005): "A unified framework for pro-poor growth analysis," Economics Letters, 89, 216-221.

FISHBURn, P. AND R. WiLlig (1984): "Transfer Principles in Income Redistribution," Journal of Public Economics, 25, 323-328.

Foster, J., J. Greer, And E. Thorbecke (1984): "A Class of Decomposable Poverty Measures," Econometrica, 52, 761-776.

HÄrDlE, W. (1990): Applied Nonparametric Regression, vol. XV, Cambridge, cambridge university press ed.

Kakwani, N., S. KhandKer, And H. Son (2003): "Poverty Equivalent Growth Rate: With Applications to Korea and Thailand," Tech. rep., Economic Commission for Africa. 
KAKWANi, N. AND E. PERniA (2000): "What is pro-poor growth?" Asian Development Review, 16, 1-22.

KLASEn, S . (2003): "In Search of the Holy Grail: How to Achieve Pro-Poor Growth?" Discussion Paper \#96, Ibero-America Institute for Economic Research, Georg-August-Universität, Gottingen.

Kolm, S.-C. (1976): “Unequal Inequalities, II," Journal of Economic Theory, 13, 82-111.

Liberati, P. (2003): "Poverty Reducing Reforms and Subgroups Consumption Dominance Curves," Review of Income and Wealth, 49, 589601.

MAKDISSI, P. AND Q. Wodon (2002): “Consumption Dominance Curves: Testing for the Impact of Indirect Tax Reforms on Poverty," Economics Letters, 75, 227-35.

MAYShAR, J. AND S. YITZHAKI (1996): "Dalton-Improving Tax Reform: When Households Differ in Ability and Needs," Journal of Public Economics, 62, 399-412.

McCulloch, N. AND B. BAulCH (1999): "Tracking pro-poor growth," ID21 insights \#31, Sussex, Institute of Development Studies.

PEN, J. (1971): Income Distribution: facts, theories, policies, New York: Preaeger.

RAO, R. (1973): Linear Statistical Inference and Its Applications, New York: John Wiley and Sons Inc.

RAVAllion, M. (2001): “Growth, Inequality and Poverty: Looking Beyond Averages," World Development, 29, 1803-15.

Ravallion, M. And S. Chen (2003): "Measuring Pro-poor Growth," Economics Letters, 78, 93-99.

Ravallion, M. AND G. DatT (2002): "Why Has Economic Growth Been More Pro-poor in Some States of India Than Others?" Journal of Development Economics, 68, 381-400.

SANTORO, A. (2007): "Marginal commodity tax reforms: a survey," Journal of Economic Surveys, 21, 827-848.

Son, H. (2004): “A note on pro-poor growth,” Economics Letters, 82, 307314. 
United Nations (2000): A Better World for All, New York.

WatTs, H. W. (1968): “An Economic Definition of Poverty," in Understanding Poverty, ed. by D. Moynihan, New York: Basic Books.

Wildasin, D. (1984): "On Public Good Provision With Distortionary Taxation," Economic Inquiry, 22, 227-243.

WORLD BANK (2002): “Globalization, Growth, and Poverty,” World bank policy research report.

Yitzhaki, S. AND J. Slemrod (1991): "Welfare Dominance: An Application to Commodity Taxation," American Economic Review, LXXXI, $480-96$.

YITZHAKI, S. AND W. THIRSK (1990): "Welfare Dominance and the Design of Excise Taxation in the Cote D'Ivoire," Journal of Development Economics, 33, 1-18.

Table 1: Shares (by population quintiles) of total expenditures on different goods and services

\begin{tabular}{l|r|r|r|r|r}
\hline \hline & \multicolumn{5}{|c}{ Expenditure shares in \% } \\
\hline Quintile & Poorest & 2 & 3 & 4 & Richest \\
\hline Goods and services & 42.99 & 28.88 & 22.61 & 17.20 & 8.04 \\
Food & 6.13 & 5.09 & 4.45 & 3.87 & 2.64 \\
Energy & 11.74 & 11.90 & 12.09 & 13.32 & 12.42 \\
Transport & 39.14 & 54.13 & 60.85 & 65.61 & 76.9 \\
Other goods & & & & & \\
\hline Shares of food expenditures & 25.88 & 23.91 & 21.20 & 18.95 & 15.90 \\
Cereals & 28.66 & 37.92 & 41.90 & 45.61 & 46.44 \\
Milk, meat and fish & 19.30 & 18.30 & 17.63 & 17.86 & 17.66 \\
Vegetables & 26.16 & 19.87 & 19.27 & 17.58 & 20.00 \\
Other food items & & & & &
\end{tabular}


Table 2: Intervals of poverty lines over which a revenue and efficiency neutral tax reform that decreases taxes on row goods and that increases taxes on column goods can be considered pro-poor (absolutely and relatively speaking)

\begin{tabular}{|l|c|c|c|}
\hline & \multicolumn{3}{|c|}{ First-order dominance } \\
\hline Goods & Food & Transport & Energy \\
\hline Food & - & $0.145-3.000+$ & $0.150-2.711$ \\
& - & $(0.190-2.971)$ & $(0.206-0.925)$ \\
Energy & $0.000-0.145$ & - & $0.000-0.137$ \\
& & - & - \\
\hline \hline & $0.000-0.150$ & $0.137-3.000+$ & - \\
\hline Goods & \multicolumn{3}{|c|}{ Second-order dominance } \\
\hline Food & Food & Transport & Energy \\
& - & $0.279-3.000+$ & $0.310-3.000+$ \\
Transport & - & $(0.375-3.000+)$ & $(0.383-2.753)$ \\
& $0.000-0.279$ & - & $0.000-0.269$ \\
Energy & - & - & - \\
& $0.000-0.310$ & $0.269-3.000+$ & - \\
\hline
\end{tabular}

Note: The intervals that appear on the first line of each cell are estimates. The intervals over which the results are statistically significant at a 95\% level are shown within parentheses on the second line of each cell. 
Table 3: Intervals of poverty lines over which a revenue and efficiency neutral tax reform that decreases taxes on row goods and that increases taxes on column goods can be considered pro-poor

\begin{tabular}{|l|c|c|c|}
\hline & \multicolumn{3}{|c|}{ First-order dominance $(s=1)$} \\
\hline Goods & Cereals & Milk, Meat and Fish & Vegetables \\
\hline Cereals & - & $0.000-2.231$ & $0.000-0.171$ \\
Milk, Meat and Fish & - & $(0.010-2.159)$ & $(0.000-0.107)$ \\
& $2.231-3.000+$ & - & $0.010-0.012$ \\
Vegetables & $(2.294-3.000+)$ & - & - \\
& $0.171-0.588$ & $0.012-2.421$ & - \\
\hline & $(0.271-0.458)$ & $(0.044-2.040)$ & - \\
\hline Goods & \multicolumn{2}{|c|}{ Second-order dominance $(s=2)$} \\
\hline Cereals & Cereals & Milk, Meat and Fish & Vegetables \\
Milk, Meat and Fish & - & $0.000-3.000+$ & $0.000-0.328$ \\
Vegetables & - & $(0.219-3.000+)$ & - \\
& - & - & $0.067-0.112$ \\
& $0.328-0.701$ & $0.067-3.000+$ & - \\
& - & $(0.196-3.000+)$ & - \\
\hline
\end{tabular}

Note: The intervals that appear on the first line of each cell are estimates. The intervals over which the results are statistically significant at a $95 \%$ level are shown within parentheses on the second line of each cell. 
Figure 1: $90 \%$ two-sided confidence intervals around relative pro-poor consumption dominance curves, $C D^{R: s}(z)$

First-order dominance $(s=1)$



Second-order dominance $(s=2)$

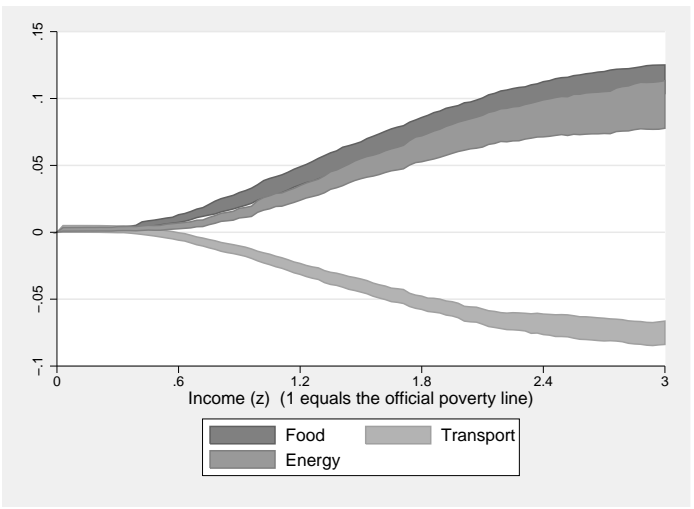

Figure 2: $90 \%$ two-sided confidence intervals around absolute pro-poor consumption dominance curves, $C D^{A: s}(z)$

First-order dominance $(s=1)$

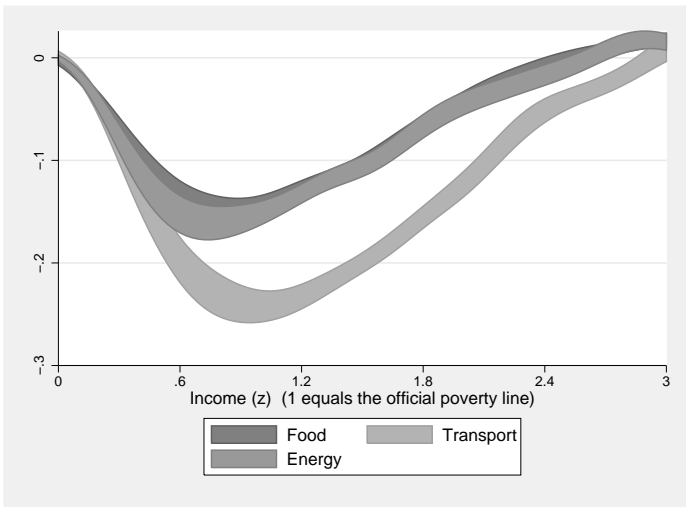

Second-order dominance $(s=2)$

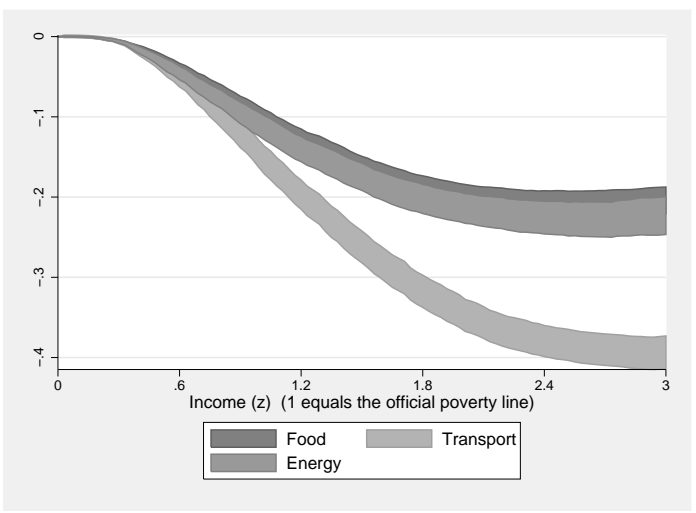


Figure 3: Difference between absolute pro-poor consumption dominance curves

$C D_{\text {Food }}^{A: s=1}(z)-C D_{\text {Transport }}^{A: s=1}(z)$

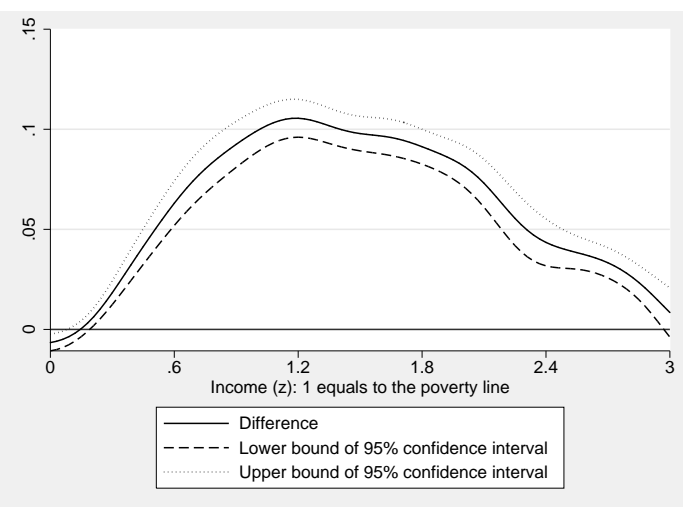

$C D_{\text {Food }}^{A: s=2}(z)-C D_{\text {Transport }}^{A: s=2}(z)$

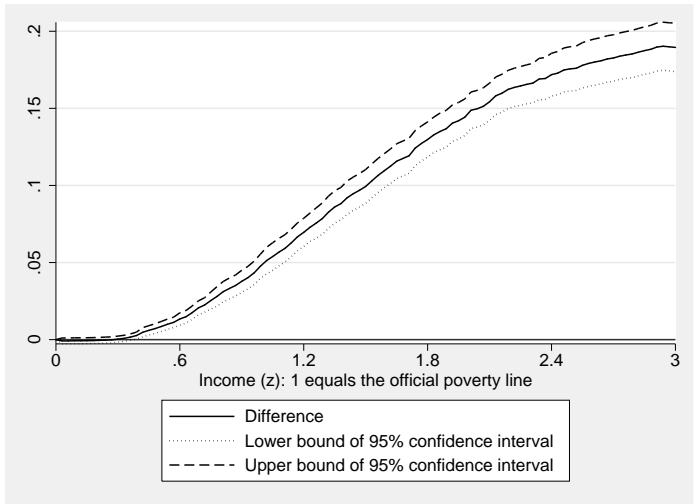

Figure 4: Difference between absolute pro-poor consumption dominance curves

$C D_{\text {Food }}^{A: s=1}(z)-C D_{\text {Energy }}^{A: s=1}(z)$

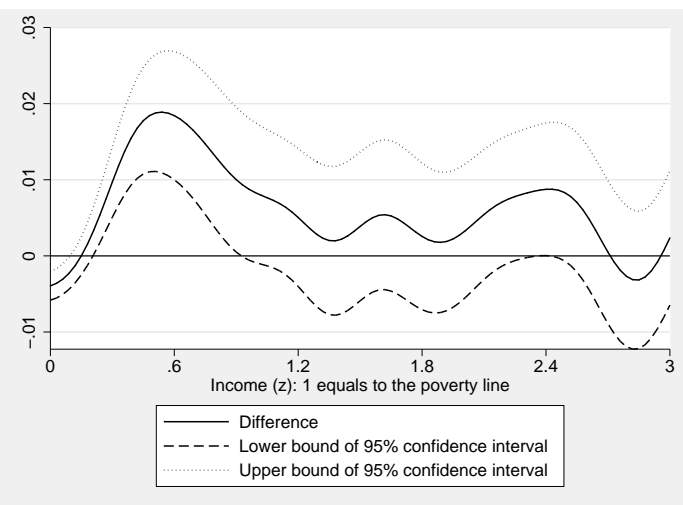

$C D_{\text {Food }}^{A: s=2}(z)-C D_{\text {Energy }}^{A: s=2}(z)$

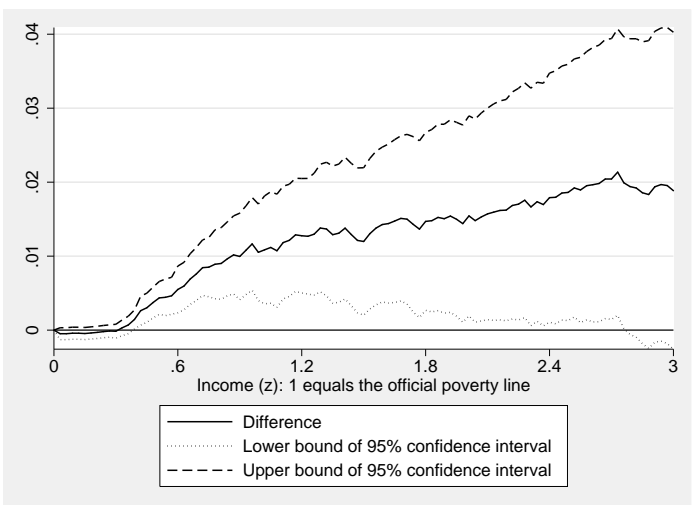


Figure 5: Difference between pro-poor consumption dominance curves

$$
C D_{\text {Cereals }}^{A: s=1}(z)-C D_{\text {Vegetables }}^{A: s=1}(z)
$$

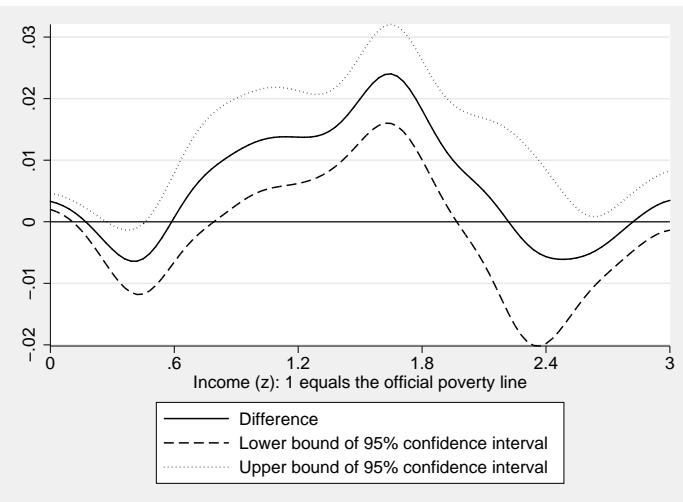

$C D_{\text {Cereals }}^{A: s=2}(z)-C D_{\text {Vegetables }}^{A: s=2}(z)$

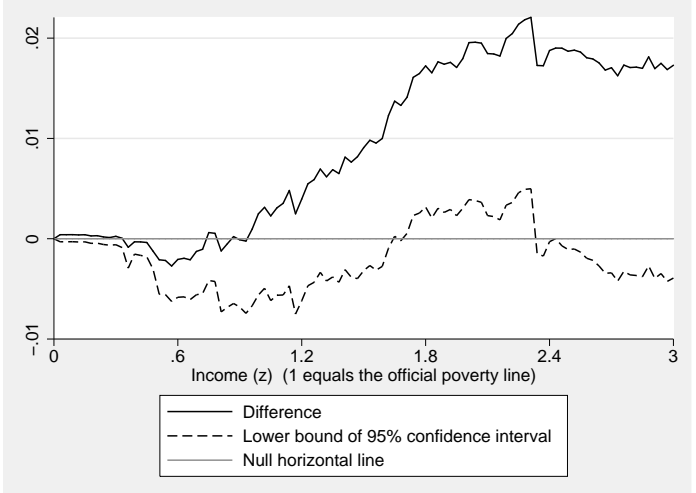

Figure 6: Difference between pro-poor consumption dominance curves, assuming that the deadweight loss from taxing Energy is twice as large as that from taxing Food

Relative pro-poorness

$C D_{\text {Food }}^{R: s=1}(z)-2 C D_{\text {Energy }}^{R: s=1}(z)$

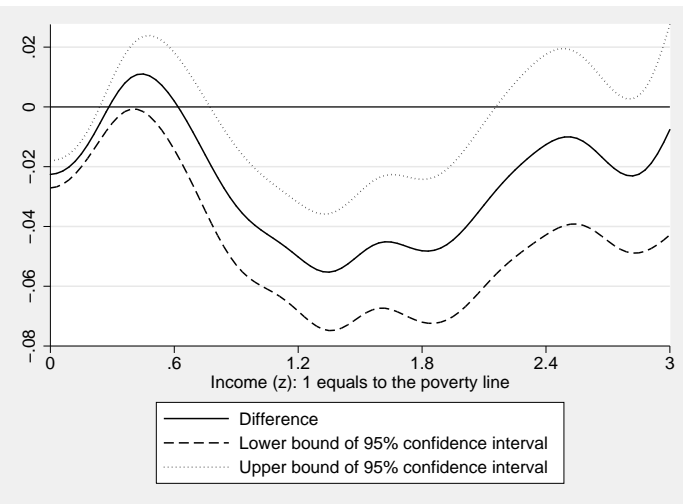

Absolute pro-poorness

$C D_{\text {Food }}^{A: s=1}(z)-2 C D_{\text {Energy }}^{A: s=1}(z)$

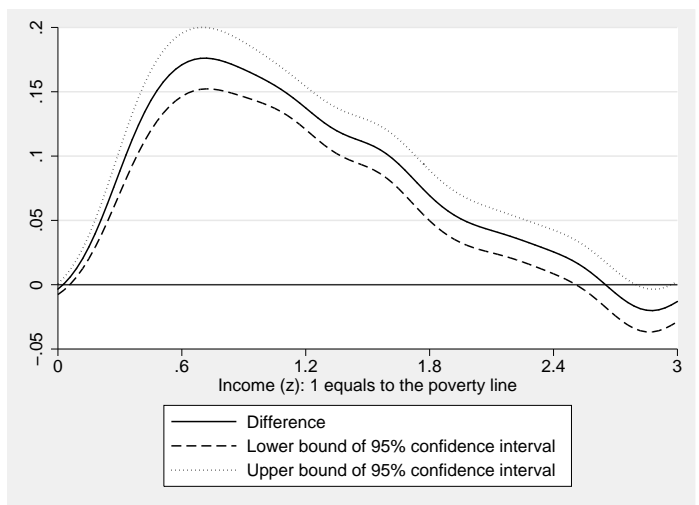


Figure 7: Difference between pro-poor consumption dominance curves, assuming that the deadweight loss from taxing Vegetables is twice as large as that from taxing Cereals

$$
C D_{\text {Cereals }}^{R: s=1}(z)-2 C D_{\text {Vegetables }}^{R: s=1}(z)
$$

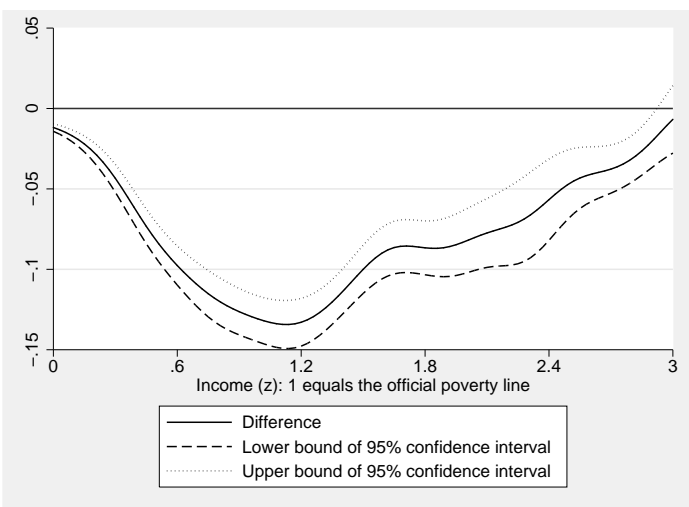

$$
C D_{\text {Cereals }}^{A: s=1}(z)-2 C D_{\text {Vegetables }}^{A: s=1}(z)
$$

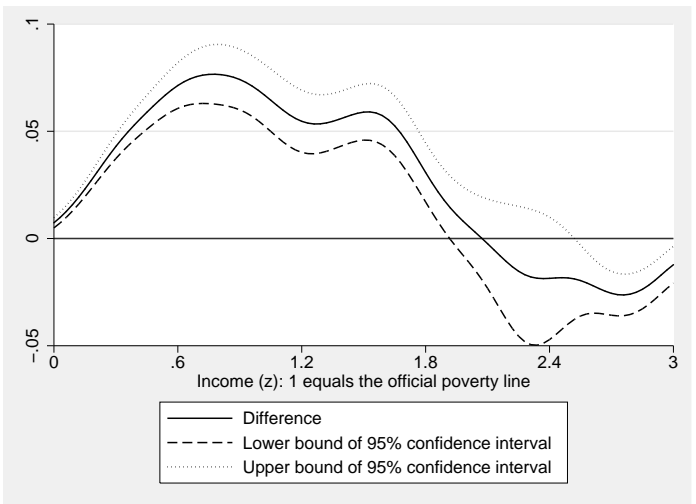

Figure 8: The ratio between pro-poor consumption dominance curves

$$
\delta_{\text {Food,Energy }}^{R: s=1}(z)
$$

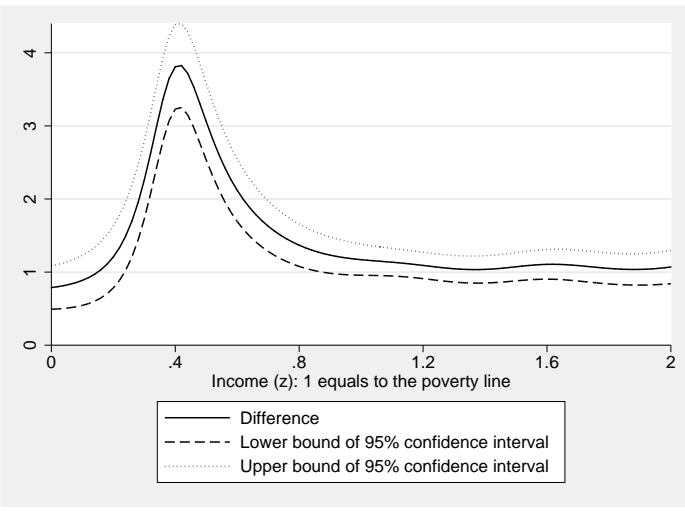

$\delta_{F \text { ood,Energy }}^{A: s=1}(z)$

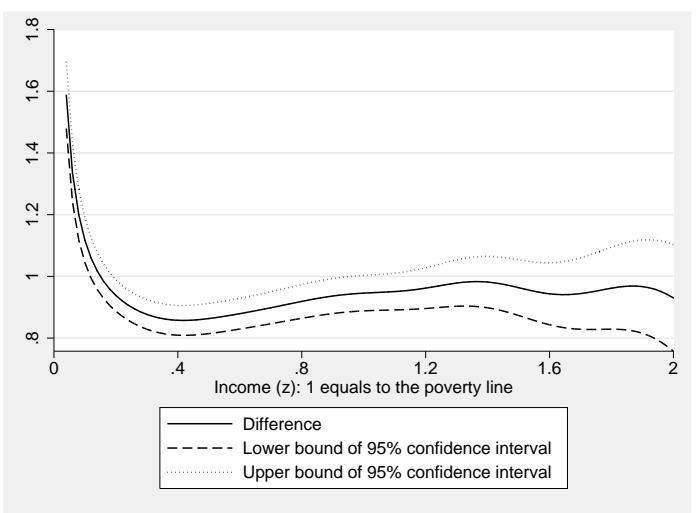

